\title{
Erratum to: Onset of Plasticity via Relaxation Analysis (OPRA)
}

\author{
A. Pandey ${ }^{1,2} \cdot$ R. Wheeler ${ }^{3} \cdot$ A. Shyam ${ }^{1} \cdot$ T.B. Stoughton ${ }^{4}$
}

Published online: 12 May 2016

(C) Society for Experimental Mechanics 2016

\section{Erratum to: Exp Mech}

\section{DOI 10.1007/s11340-016-0152-3}

The authors regret the following error. We have incorrectly uploaded the wrong Fig. 5(c). The correct figure is as shown here.

The online version of the original article can be found at http://dx.doi.org/ 10.1007/s11340-016-0152-3.

A. Pandey

dramitpandey@gmail.com

1 Materials Science and Technology Division, Oak Ridge National Laboratory, Oak Ridge, TN 37831, USA

2 Present address: Rolls Royce LG Fuel Cell Systems Inc., North Canton, OH 44720, USA

3 MicroTesting Solutions LLC, Columbus, OH 43026, USA

4 General Motors Research and Development Center, Warren, MI 48090, USA

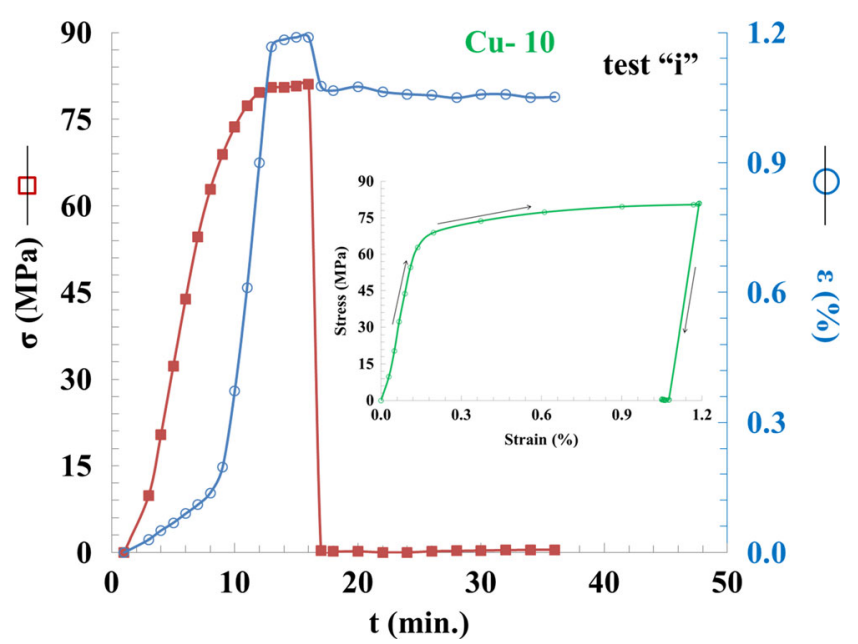

Fig. 5 (c) Stress-time response (squares) and strain-time response (circles) for a $\mathrm{Cu}-10$ sample loaded rapidly to a maximum stress (81 MPa) above the OPRA yield point (58 MPa) and then unloaded rapidly. Inset shows the stress-strain curve for this load-unload test which includes extensive plastic flow as well as anelastic strain recovery. 